\title{
DIÁLOGOS COM A HISTÓRIA DA EDUCAÇÃO PROFISSIONAL NO BRASIL: PERMANÊNCIAS E CONTRADIÇÕES
}

\author{
DIÁLOGOS CON LA HISTORIA DE LA EDUCACIÓN VOCACIONAL EN BRASIL: \\ PERMANENCIES Y CONTRADICCIONES
}

\section{DIALOGS WITH THE HISTORY OF PROFESSIONAL EDUCATION IN BRAZIL: PERMANENCES AND CONTRADICTIONS}

DOI: http://dx.doi.org/10.9771/gmed.v12i1.34909

\author{
Mad Ana Desirée Ribeiro Castro ${ }^{1}$ \\ Claudia Borges Costa Costa ${ }^{2}$ \\ Sebastião Cláudio Barbosa ${ }^{3}$
}

\begin{abstract}
Resumo: O presente trabalho versa sobre a História da Educação Profissional no Brasil e propõe desvelar algumas permanências e algumas contradições constituídas ao longo desse percurso histórico, principalmente, no âmbito da Rede Federal de Ensino. Por um lado, a análise das permanências educativas traduz as construções e os desdobramentos que impediram e impedem a constituição da educação sob o ponto de vista emancipatório. Por outro, propõe a reflexão sobre as contradições que apontam para a possibilidade de uma formação que possui como marca a indissociabilidade entre teoria e prática, por meio da formação integrada.
\end{abstract}

Palavras Chaves: Educação Profissional; História; Permanência; Contradição.

Resumen: El presente trabajo trata de la Historia de la Educación Vocacional en Brasil y se propone revelar algunas permanencias y algunas contradicciones constituidas a lo largo de este curso histórico, principalmente, dentro de la Red Federal de Educación. Por un lado, el análisis de las permanencias educativas refleja las construcciones y desarrollos que han impedido e impedido la constitución de la educación desde un punto de vista emancipatorio. Por otro lado, estos escritos proponen la reflexión sobre las contradicciones que apuntan a la posibilidad de una formación que tenga como marca la indisociabilidad entre teoría y práctica, a través de la formación integrada.

Palabras clave: Educación profesional; Historia; Permanencia; Contradicción

Abstract: The present work approaches the History of Professional Education in Brazil and reveal some permanences and some contradictions built up during this historical course, mainly within the Federal Education Network. The analysis of educative permanences translate the constructions and unfoldings which stopped and still stops the constitution of education under the emancipatory point of view. On the other hand, these writings propose the reflections about the contradictions, which highlights the possibility of a formation which possess as its greatest mark the inseparability between theory and practice.

Keywords: Professional Education; History; Permanences; Contradictions.

\section{Introdução}

Hobsbawn, (1988, p.22) em seu livro Escritos Sobre a História, diz que:

Ser membro de uma comunidade humana é situar-se em relação ao seu passado (ou da comunidade), ainda que para apenas rejeitá-lo. O passado 
é, portanto, uma dimensão permanentemente da consciência humana, um componente inevitável das instituições, valores e outros padrões da sociedade humana.

A relação entre passado, presente e futuro, componentes fundantes da História, pois delimita quando e onde os homens desenvolvem suas ações, requer um olhar atento, perspicaz e vigoroso para se compreender o tempo presente e, ao menos tendencialmente, pensar os desdobramentos futuros. Nesta relação, o passado assume centralidade. Nele se concentra a verdade humana que, a partir do entendimento de Marx, é prática, é algo feito, desenvolvido, portanto, não está no âmbito da especulação do pensamento. É quando/onde concentra a gênese do que continua, permanece. Também é, tendo o presente como ponto que estabelece a relação, o lócus possível de apreensão das mudanças e transformações.

Posto isto, o presente trabalho tem como objetivo analisar, por um lado, as permanências educativas, ou seja, as ações e pensamentos que constituem a estrutura da Educação Profissional, construídos ao longo destes mais de quinhentos anos de História e que nos desdobramentos do presente aparecem, na maioria das vezes, como impeditivos para a realização de uma educação emancipatória. Isto porque, segundo o que se compreende de Marx, "os seres humanos fazem a sua própria História, mas não a fazem segundo a sua vontade ou escolha. A fazem sim, mas sob as circunstâncias e possibilidades reais, com as quais se defrontam diretamente, e que são legadas pelo passado. Fica claro, então, que, as tradições passadas, aparentemente mortas, parecem não saber seu lugar, pois, ficam no presente atormentando "como um pesadelo", os humanos" (MARX, s/d, p. 203).

Por outro lado, confrontando-se dialeticamente com esta lógica dominante, ações e pensamentos oriundos da Educação Profissional buscam estabelecer condições econômicas, políticas e pedagógicas que retomam a relação entre trabalho e educação em uma perspectiva de integração entre Educação Básica e Educação Profissional pela via do desenvolvimento do currículo integrado e da omnilateralidade. Esta perspectiva visa superar a fragmentação educativa e retomar a realização de cursos que consideram o processo formativo como ato fundamentado na compreensão de que os homens são e se constituem como seres inteiros e não divididos, cindidos. A construção histórica predominante na Educação Profissional ancora-se no tecnicismo. Isto é, na restrição do homem ao âmbito do fazer produtivo básico, que adestra o corpo e limita seu pensar, seu sentir e seu agir.

A partir de tais pressupostos e objetivos mencionados, a compreensão da História da Educação Profissional, das suas permanências e contradições, busca dar sentido ao passado, recuperando seu peso limitante no tempo presente e evidenciando as possibilidades de superação desta opressão. Estas são as reflexões propostas neste escrito.

\section{Sociedade brasileira e educação: ponderações necessárias}

Quais são as condições históricas que constituíram a Educação Profissional no Brasil? Quais estruturas têm fomentado estas condições? Na tentativa de dar resposta a tais questões, 
percebe-se que a formação social brasileira, nas condições de colônia, império e depois de república, assenta-se sob os pilares da dependência externa, de Portugal e Espanha, como estatuto político, e dos países centrais do capitalismo, como estatuto econômico.

$\mathrm{Na}$ passagem para a situação republicana/capitalista, a opção pela manutenção dos laços de dependência foi feita pelas elites como forma de manutenção do ethos econômico fundamentado no latifúndio, ainda com forte tradição cultural escravista. O objetivo foi o de livrar-se fundamentalmente das amarras coloniais. $\mathrm{O}$ apego aos princípios e a algumas práticas liberais dá-se na medida em que convém à elite, de acordo com as necessidades de redefinição das "relações de dependência que continuariam a vigorar na vinculação do Brasil com o mercado externo e as grandes potências da época." (FERNANDES, 1975, p. 34).

Oliveira (2003) alerta para o fato que a relação de dependência é projeto da elite nacional, que tem preferido a relação subordinada aos países centrais do que desenvolver-se de forma autônoma na construção de um capitalismo que dispute com os centros dominantes a partilha da riqueza internacional. Diz, portanto, que não há um projeto de saída do ‘subdesenvolvimento’, pois ele mesmo, enquanto dependência, é opção que as elites fizeram no chamado processo de modernização da sociedade, a partir da arrancada para a industrialização em 1930.

O custo social deste desenvolvimento é alto. Observa-se que a ampliação do capital interno se deu a partir da superexploração da classe trabalhadora, da concentração exponencial da renda, da propriedade e do poder (OLIVEIRA, 2003). Nesta perspectiva, a preservação de estruturas e funções democráticas, de dimensão liberal burguesa, favorece aqueles que têm o monopólio do poder. As transformações se dão sempre dentro da ordem e visam, quando necessárias, ampliar os privilégios dos "sócios", desde os menores até os maiores. (FERNANDES, 1975).

Sobre a Educação, neste contexto, o que se tem é que historicamente a formação de trabalhadores tem se restringido à Educação Profissional (submetida ao mercado e ao tecnicismo), enquanto que a educação acadêmica, livresca, destina-se à elite, claramente deliberada ao prosseguimento dos estudos em nível secundário (hoje, médio) e superior. Para Frigotto, Ciavatta e Ramos (2005, p.32), o "dualismo se enraíza em toda a sociedade através de séculos de escravismo e discriminação do trabalho manual". Nestes termos, o lugar educacional torna-se um distintivo de classe. Segundo Kuenzer (2007), a formação profissional assume a condição do país na divisão internacional do trabalho. No caso brasileiro, ela tem natureza elementar e restrita, mesmo dentro da lógica da produção flexível em que as atividades têm exigido maior complexidade cognitiva e aporte de conhecimento científico.

Por fim, o movimento histórico que constrói a Educação Profissional, se por um lado cria hegemonicamente o contexto tratado anteriormente, por outro, apresenta as contradições, que desvelam, contra hegemonicamente, as lutas sociais que buscaram (e buscam) efetivar, manter e ampliar os direitos sociais e uma educação emancipatória. 


\section{Permanências e contradições da Educação Profissional brasileira}

No período colonial (1500-1822), a Educação Profissional desenvolveu-se como produção básica necessária à sobrevivência dos grupos que vieram para efetivar o processo de colonização do Brasil. Ela começa a ser realizada pelos jesuítas juntamente com os povos nativos - que foram os primeiros "mestres" de artes e ofícios; ensinaram as técnicas e confeccionaram tecelagem, cerâmica, adornos, artefatos para a guerra, de construção de casas assim como o cultivo e a produção de medicamentos - para auxiliar no processo de expansão do catolicismo e ocupação de terras. Neste momento ainda, desenvolveu-se a formação de trabalhadores escravos - normalmente eram escolhidos, dentre os escravizados, aqueles com força física, habilidade, atenção e que mantinham lealdade aos senhores - para o desempenho de ofícios ligados à agroindústria açucareira, inicialmente. (MANFREDI, 2003).

Este contexto traz a gênese do desprezo e da pouca valorização da Educação Profissional. Afinal, evidencia a marca do trabalho de natureza física e manual, que não necessitava nem mesmo da formação básica, das primeiras letras e do domínio das operações simples de matemática para se desenvolver. Forjou-se historicamente a identificação da formação profissional como sendo coisa de "pretos", pobres, analfabetos, todos, enfim, que não estão "destinados" a prosseguir os estudos.

No período imperial 1822-1889), a formação profissional passou a ser ofertada pelas academias militares, entidades filantrópicas e liceus de artes e ofícios, construídos para atender as necessidades políticas, econômicas e sociais da nova condição do Brasil. Houve necessidade de qualificar profissionais para atuação administrativa assim como de funções mais complexas no âmbito do trabalho (MANFREDI, 2003). Nota-se que, se antes a formação profissional prescindia da alfabetização, aqui, dando continuidade a esta condição, ela foi apartada da formação secundária e superior. Dessa maneira, o processo perverso de separação formativa também vai mostrando sua gênese.

Neste momento, construiu-se também a vinculação da formação profissional com a caridade e a necessidade de formação de trabalhadores menos qualificados, constituídos pelos pobres e excluídos (órfãos, abandonados e desvalidos). Além disto, a educação profissional foi utilizada como instrumento de disciplinamento dos trabalhadores e de afirmação de uma sociedade hierarquizada.

Na primeira república (1889-1930), a formação profissional foi mantida a partir dos liceus com ampliação para outros estados e terminou constituindo iniciativa para a construção de escolas profissionalizantes no âmbito nacional. Foram criadas redes de escolas pelos governos e pela Igreja Católica. O novo contexto, agora republicano e capitalista, contudo, marcado pelo triunfo dos latifundiários agroexportadores na forma do 'caudilhismo tupiniquim' explicado pelo coronelismo, nos moldes de um país dependente e subordinado, fez permanecer as características anteriores da Educação Profissional, apesar da sua nova institucionalidade e extensão. 
Contudo, com a chegada constante e em massa de imigrantes ao Brasil, a partir de 1860, e a constituição de outra natureza de trabalho, ocorre a promoção de novas possibilidades teóricas e metodológicas para a formação profissional. Na década de 1910 são criadas Escolas Operárias, bibliotecas populares e Escolas Modernas ou Racionalistas, constituídas pelos anarquistas, anarcosindicalistas e socialistas pautadas na concepção de educação integral, racional, mista e solidária.

Nesse interim, e por causa, em grande medida, da ação de imigrantes europeus que traziam ideias libertárias e socialistas, o debate sobre a formação integrada fez parte de uma construção histórica, tecida pelos movimentos sociais. Assim, enquanto iniciativa de "Educação Popular", o Brasil vivenciou, dentro dos limites impostos pelo contexto social e de efetivação prática das propostas, alguns projetos educacionais fundamentados na defesa da educação integrada. Conforme Moraes (2013, p. 9), desenvolveu-se, na nossa compreensão, contra hegemonicamente, uma proposta de levar o trabalhador "[...] à sua formação integral e consciência de classe", por isso, construíram "[...] diversas bibliotecas populares, centros de estudos, centros de cultura social, grupos de teatro, centros libertários, sem mencionar os variados jornais - mensais, semanários, diários, revistas - que obtiveram significativa ressonância na classe operária e na sociedade da época".

A partir de 1930, com o início da arrancada industrial, a formação profissional foi organizada pelos projetos estatais e privados. Pela primeira vez na história do Brasil, o trabalho foi assumido como "base da riqueza da nação", como preconizava Adam Smith, no século XVIII. Nessa perspectiva, a primeira escola profissional foi "[...] a mecânica, que funcionava no Liceu de Artes e Ofícios e era mantida por companhias ferroviárias paulistas, com recursos do Ministério da Agricultura". (MANFREDI, 2003, p. 88).

Abrindo aqui um parêntesis histórico e cronológico, é preciso lembrar, que, como presidente da república, Nilo Peçanha (1909 a 1910) instaurou uma rede de 19 escolas de aprendizes e artífices, "para os desvalidos da sorte", dando início à Rede Federal de Ensino. Como expressão de contradição em relação a este mencionado período, estabeleceu-se a Reforma de 1932, no Rio de Janeiro, quando Anísio Teixeira transformou o Instituto Profissional João Alfredo em Escola Técnica Secundária, uma primeira tentativa de superar a separação entre trabalho manual e trabalho intelectual.

Voltando ao raciocínio anterior ao parêntesis, a trajetória de concretização das ideias de Ford e Taylor no Brasil, representando respectivamente, o estabelecimento da linha de montagem e o cronômetro nos processos produtivos industriais, em 1931, foi cenário do surgimento do Instituto de Organização Racional do Trabalho (IDORT). A alta diretoria era composta por empresários paulistas, os quais cuidaram de disseminar e consolidar, os princípios e técnicas tayloristas (VARGAS, 1985).

Para atender a este novo padrão de desenvolvimento do capitalismo brasileiro, a Educação Profissional passou a ter importância para a formação da classe trabalhadora, tendo como objetivo sua acomodação em relação aos mecanismos de disciplinamento e treinamento da força de trabalho, pautados nos fundamentos do taylorismo e do fordismo. Pode-se dizer que essa formação se 
concretizou de forma mais ampla, posteriormente, na década de 1940, com a criação do denominado "Sistema S". Tal Sistema, ancorado nas Federações da Indústria e do Comércio, acentua e torna política educacional a formação profissional desvinculada de outras dimensões que constituem o homem.

No cenário de 1945-1964, por um lado, o Estado continuou sendo o principal protagonista dos planos, projetos e programas de investimentos que alicerçaram o parque e o empresariado industrial e da formulação das políticas educacionais fundamentadas na permanência e legitimação institucionalizada da separação entre o trabalho manual e trabalho intelectual. Neste sentido, o Estado recompõe, de maneira aprofundada e ampliada, a dualidade educacional, reitera-se, a destinação de uma escola para as classes dirigentes e outra para os trabalhadores. (MANFREDI, 2003)

Por outro lado, tem-se, desde a década de 1950 até o início de 1970, em relação à educação integrada, a implementação dos Ginásios Vocacionais, no Estado de São Paulo que contavam com educadores militantes da educação democrática, os quais defendiam a apropriação pela classe trabalhadora dos conhecimentos socialmente construídos. A proposta do currículo integrado destas escolas apresentou, conforme Moraes (2013, p. 994), “o trabalho como princípio educativo e os recursos pedagógicos do estudo do meio, na aproximação entre escola e cidade (polis), a participação coletiva, a autogestão e a auto avaliação [...]”. Essa formação e movimento contaram com o envolvimento da comunidade local e o estímulo à participação política dos sujeitos envolvidos.

A conjuntura seguinte colocou o Estado Militar como principal promotor de acumulação de capital. Assim, do início ao fim do regime militar, de Castelo Branco (1964-1967) a João Figueiredo (1979-1985), os presidentes do país escolheram o caminho que priorizava o desenvolvimento econômico a partir de projetos nacionais, sem, contudo, romper os laços de dependência com os países centrais do capitalismo, especialmente com os Estados Unidos da América.

Esse ideário desenvolvimentista e dependente, assim como suas necessidades educativas, deram vigor ao "Sistema S", bem como a empresas privadas e estatais por meio da Lei 6.297/1957, que, desde essa época, já conferia incentivos fiscais para as empresas realizarem cursos de formação aos empregados. Para Manfredi (2003, p. 104-105) a regulamentação da referida lei destinava "às pessoas jurídicas a possibilidade de deduzir do lucro tributável, para fins de imposto de renda, o dobro das despesas realizadas, no País, com projetos de formação profissional previamente aprovados pelo Ministério do Trabalho”.

Outra significativa ação educacional que se vinculou às necessidades formativas das demandas econômicas foi a promulgação da Lei 5.692/1971, por meio da qual instituiu-se a equiparação entre os cursos secundário e o técnico e a profissionalização compulsória do segundo grau, seguindo o pressuposto de terminalidade.

A perspectiva de uma possível articulação entre educação básica e formação profissional contida na Lei repercutiu como importante possibilidade de superação da dualidade educacional. No entanto, no que tange à profissionalização, este recurso legal não obteve muito êxito. Conforme Oliveira (2003 a), vários foram os motivos para o insucesso: a falta de investimento na formação dos 
professores, nos espaços e na infraestrutura pedagógica. Ademais, ao longo dos anos, a Lei n. 5.692/1971 foi sofrendo mudanças até 1982, quando outras leis foram surgindo e retomando a separação entre educação básica e formação profissional.

O contexto educacional produzido pela Lei n.5.692/1971, na contramão do fracasso da profissionalização compulsória, resultou, no âmbito da Rede Federal - por meio das escolas técnicas, dadas as condições de trabalho docente e da infraestrutura física e pedagógica destas instituições - na promoção de uma educação pública de qualidade, assentada na formação integrada. E esta se constitui hoje em possibilidade concreta de buscar novos caminhos e identidade para o Ensino Médio no Brasil.

As décadas de 1970 e 1980 foram marcadas pela crise do modelo taylorista e fordista. No campo econômico e social, a derrocada dos níveis de produção e produtividade, com o aumento da inflação e aumento do desemprego, combinado com os baixos salários, a contenção de investimentos nas políticas que buscaram o fortalecimento do Estado de Bem-Estar, somados à desorganização das relações econômicas internacionais, estabeleceram os elementos, que, atuando de forma conjunta, fundamentaram a crise nesse período. Um novo processo produtivo, e novas relações entre trabalho e capital passaram então a ser efetivados. Desse modo, a opção foi a produção por demanda (just in time) e a flexibilização do trabalho e de todas as suas relações trabalhistas.

Nesse diapasão, a educação também ganhou novas perspectivas. Contudo, permaneceram os fundamentos do tecnicismo, que assume agora as demandas por uma formação ancorada nas competências e habilidades, mais vinculadas às necessidades de um mercado flexível e movido por tecnologias associadas à microeletrônica e informática (FRIGOTTO, 1998).

Para a sociedade brasileira, esse debate adquiriu reconhecimento, sobretudo a partir da década de 1990, e trouxe como demanda do mercado a reestruturação do ensino médio e profissional.

Na perspectiva da contradição, na década de 1980 e 1990, os movimentos sociais e a academia fomentaram discussões sobre a educação integrada, motivadas pelo processo de elaboração da Carta Constitucional e da Lei de Diretrizes e Bases da Educação. Nesse cenário, o $5^{\circ}$ Congresso da Central Única dos Trabalhadores (CUT), por exemplo, discutiu e aprofundou o entendimento de que a formação profissional não deveria ser separada da educação geral.

A Lei de Diretrizes e Bases da Educação de 1996, a Política Nacional de Formação do Trabalhador-PLANFOR, de 1995, e o Decreto Federal n. 2.208, de 1997 estabeleceram os fundamentos para a Educação Profissional.

A LDB (BRASIL, 1996) prevê a formação profissional afinada com a nova configuração do trabalho, isto porque afirma como importante "a preparação básica para o trabalho e para a cidadania do educando, para continuar aprendendo, de modo que seja capaz de se adaptar com flexibilidade às novas condições de ocupação ou a aperfeiçoamentos posteriores". Nesse sentido, o ensino médio não se caracteriza como etapa do processo de desenvolvimento humano, mas objetiva formar o cidadão por meio de conhecimento e competências para o mercado de trabalho.

Aprofundando as orientações da LDB, na perspectiva da vinculação da educação às 
demandas do mercado, o Decreto Federal n. 2.208/1997, que regulamenta a LDB em seus artigos 39 a 42, retoma a separação entre formação geral e formação profissional.

A Política Nacional de Formação do Trabalhador-PLANFOR foi um plano nacional do segundo período do governo FHC (1995-2002), desenvolvido pelo Ministério do Trabalho, sob a coordenação da Secretaria de Formação e Desenvolvimento Profissional, em alguns estados brasileiros. Esse programa foi desenvolvido por meio de convênios com outras instituições e teve como finalidade habilitar trabalhadores que se encontravam empregados ou desempregados. Os cursos não foram formatados para que houvesse a elevação da escolaridade dos trabalhadores, o que seria possível com a integração da educação básica. Possuía caráter provisório e era organizado de forma adjacente a entidades de classe e projetos de governo.

Em contraponto às perspectivas do governo FHC, em 1995, como mencionado anteriormente, o III Congresso dos Trabalhadores Metalúrgicos (CNM/CUT) aprovou o Programa Integrar que teve como objetivo reafirmar a formação profissional, mas, distante do ideário de adestramento, da rotina de cursos isolados e aligeirados e formação compartimentalizada. No $8^{\circ}$ Congresso Nacional da CUT consolida-se uma proposta de Educação Integral dos Trabalhadores, inclusive com o objetivo de intervir nas políticas públicas.

Em 2004, no governo Lula (2003-2010), surge a possibilidade de um novo desenho na qualificação do trabalhador, fruto de discussão por parte dos movimentos sociais e da academia, que almejavam o fim da dualidade entre educação básica e profissional. Neste período foram fomentados debates em seminários nacionais coordenados pelo Ministério da Educação e do Trabalho, o que resultou na promulgação do Decreto n. 5.154/2004. Por meio desse decreto houve a retomada da possibilidade de integração entre educação profissional e educação básica. Para Moraes (2013, p. 996), esse decreto estimulou “o Ministério da Educação (MEC) a promover iniciativas que propiciassem o amadurecimento de orientações dirigidas à superação organizacional e pedagógica da separação entre formação geral e técnica, entre trabalho, cultura, ciência e tecnologia”.

Na esteira desse ideário surge o Programa Nacional de Integração da Educação Profissional com a Educação Básica na modalidade de Educação de Jovens e Adultos (Proeja) e o Proeja-Fic (Formação Inicial e Continuada). Para Machado (2011), o Proeja, embora constituído como programa e não como política pública, era a possibilidade de suprir a carência histórica, no país, de uma proposta pedagógica que pudesse integrar formação geral e profissional na Educação Básica no segmento Fundamental e Médio e destinada aos estudantes que não puderam concluir a formação básica na chamada "idade regular".

Para Moura (2010), esse contexto de incoerências e disputas de poder em torno de um projeto de educação para os trabalhadores, indicou a necessidade de debates que se cristalizaram nas conferências nacionais que aconteceram a partir de 2006, a saber, a Primeira Conferência Nacional de Educação Profissional e Tecnológica (CONFETC), em 2008; a Conferência Nacional de Educação Básica (CONEB), em 2009; e a Conferência Nacional de Educação - CONAE, em 2010. Os relatórios e documentos constituídos a partir dessas discussões marcaram um consenso em torno 
das contradições e polêmicas que fizeram parte do debate. Percebe-se, a partir de vários pontos de vista, por um lado, que a sustentação da dualidade estrutural entre Ensino Médio e Educação Profissional continua sendo defendida e mantém a histórica condição do ensino propedêutico para alguns poucos filhos da elite, e, por outro lado, a Educação Profissional para suprir mão de obra para o mercado, destinada aos filhos dos trabalhadores.

Em 2011, no governo Dilma (2011-2016), outro programa foi estabelecido por força da Lei n.12.513. Era mais um prenúncio do caráter do projeto de privatização do governo federal, antagônico à defesa da formação integrada entre educação básica e profissional. Conforme Moraes (2013, p.996), o "Programa Nacional de Acesso ao Ensino Técnico e Emprego (Pronatec) (Lei n. 12.513/11), [...] expressa o recrudescimento da disputa política no âmbito governamental e um retrocesso aos tempos do Decreto n. 2.208/97, instituído no Governo Fernando Henrique Cardoso”. Esse programa apresentou objetivos claros, isto é, ajustar os trabalhadores - empregados ou desempregados - ao mercado e motivar as redes estaduais a assumirem o Ensino Médio na sua forma concomitante à Educação Profissional, preferencialmente por meio de um termo de parceria com o "Sistema S". Esse projeto foi mais um dos permanentes programas da qualificação profissional historicamente constituído no país e revela, nessas idas e vindas, muitas vezes contraditórias, a força da perspectiva que impõe a formação para o mercado, que, enfim, significa a reafirmação da desqualificação do trabalho braçal e da dualidade educacional.

Entretanto, pela via da crítica ou da contradição, por meio da Lei 13.005 de 25 de junho de 2014 foi publicado o Plano Nacional de Educação (PNE) estabelecendo vinte metas para a Educação no Brasil. No que tange à Educação Profissional, o PNE destaca em suas metas dez, onze e doze, que pretendia:

[...] Meta 10: Oferecer, no mínimo, 25\% (vinte e cinco por cento) das matrículas de educação de jovens e adultos, nos ensinos fundamental e médio, na forma integrada à educação profissional.

Meta 11: Triplicar as matrículas da educação profissional técnica de nível médio, assegurando a qualidade da oferta e pelo menos $50 \%$ (cinquenta por cento) da expansão no segmento público. (BRASIL, 2014)

Percebe-se a preocupação com uma política de inclusão social, que, parafraseando Luiz Carlos de Freitas, faz parte de uma "geocultura da inclusão social", caracterizada pela expansão e valorização dos serviços púbicos, e as perspectivas de integração da formação geral com a formação para o trabalho. Contudo, a partir de 2015, a implementação do PNE enfrentou muitas dificuldades, pois a política econômica desenvolvida por Dilma no seu segundo mandato, que foi interrompido em 2016, se perdeu e, de fato, se submeteu às perspectivas neoliberais, inviabilizando o alcance de tais metas. As crises econômicas (externa e interna), somadas à crise política interna, fragilizaram e paralisaram o governo federal. O resultado impeachment da presidenta Dilma Rousseff

Após o golpe ocorrido em 2016, houve a retomada dos princípios pedagógicos neoliberais ancorados no desenvolvimento de "habilidades e competências", preconizados durante o governo FHC, e que dessa vez, se estabeleceria por meio da implementação de uma Base Nacional Comum Curricular (BNCC). As discussões acerca da BNCC já vinham ocorrendo desde o final de 2015, ainda 
durante o governo Dilma, com apresentação de um texto preliminar, intitulado Pátria Educadora: a qualificação do Ensino Básico como obra de construção nacional, buscando estabelecer um currículo mínimo para os Ensinos Fundamental e Médio, que é uma orientação presente na LDB de 1996.

Dessa maneira, mesmo que a BNCC não esteja diretamente relacionada à Educação Profissional, cabe uma menção a ela, uma vez que sua pretensão é interferir, para pior, em todas as estruturas das políticas educacionais do Brasil. Dessa forma, após muitas críticas do campo progressista atuante na educação, foi apresentado o texto final da BNCC pelo MEC ao CNE, em abril de 2018, apontando que:

[...] o foco no desenvolvimento de competências tem orientado a maioria dos Estados e Municípios brasileiros e diferentes países na construção de seus currículos. É esse também o enfoque adotado nas avaliações internacionais da Organização para a Cooperação e Desenvolvimento Econômico (OCDE), que coordena o Programa Internacional de Avaliação de Alunos (Pisa, na sigla em inglês), e da Organização das Nações Unidas para a Educação, a Ciência e a Cultura (Unesco, na sigla em inglês), que instituiu o Laboratório Latino-americano de Avaliação da Qualidade da Educação para a América Latina (LLECE, na sigla em espanhol). Ao adotar esse enfoque, a BNCC indica que as decisões pedagógicas devem estar orientadas para o desenvolvimento de competências. [...] a explicitação das competências oferece referências para o fortalecimento de ações que assegurem as aprendizagens essenciais definidas na BNCC. (MEC, 2018, p. 15)

O texto deixa claro que a BNCC retoma as perspectivas das "habilidades e competências", mas, agora com um apelo novo que pode ser resumido pelo termo neoliberal accountability (responsabilização) que fixa um pensar e um fazer educativos a partir do gerencialismo, da padronização e do ranqueamento competitivo entre as escolas por meio de supervisão externa, a saber, por exemplo, OCDE, PISA, UNESCO, Banco Mundial. A partir da compreensão de Gentili (1996), que, em seu texto já apontava essa tendência no final da década de 1990, percebe-se que as escolas, a partir do que aponta o texto da BNCC, devem ser pensadas e avaliadas pelo resultado e não pelo processo educativo, como se fossem empresas submetidas ao processo produtivo capitalista.

Segundo Gentili (1996/2017, snp) “[...] a grande operação estratégica do neoliberalismo consiste em transferir a educação da esfera da política para a esfera do mercado questionando assim seu caráter de direito e reduzindo-a a sua condição de propriedade”. Desse modo, submetida à economia de serviços, a noção de cidadania, na visão do autor, é privatizada, uma vez que "[...] o modelo de homem neoliberal é o cidadão privatizado, [...] o consumidor". Concordando com tal perspectiva, Freitas (2019), aponta que o estabelecimento da BNCC no Brasil, está de acordo com a implantação, em escala mundial, orientada pela OCDE e recomendada pelo PISA, de uma “geocultura meritocrática excludente", em substituição à "geocultura da inclusão social". Segundo Freitas (2019, snp) denuncia, o que importa

[...] é a vivência da concorrência e da disputa em cada sala de aula, bem como a ideia de que são seus resultados (positivos ou negativos) que devem ser a base de uma política educacional. A concorrência é ensinada à juventude como princípio geral de funcionamento social. [...] constróise uma sociedade cuja estratificação social, produto da desigualdade 
socioeconômica, passa a ser explicada pela estratificação meritocrática: a desigualdade dever-se-ía ao "mérito" que cada um acumula - sendo cada um responsável por si mesmo e não dependente do Estado.

Nos tempos atuais, no mandato de Jair Bolsonao (2019 a 2022), observa-se a continuidade da retomada da pedagogia das competências. Esta, juntamente com as doutrinas pedagógicas das escolas cívico-militares, e o forte ataque ao que este governo tem chamado de "marxismo cultural" compõem o leque de princípios que buscam, de forma extrema e aparentemente confusa e desarticulada, em termos educacionais, mobilizar, tendo o passado nos ombros, a síntese entre o velho e o novo, repondo a histórica modernização conservadora do país. Na verdade, o que se pode perceber é que tal confusão e desarticulação, parece compor um "plano de desmonte" das perspectivas inclusivas desenvolvidas, mesmo que a duras penas e com várias idas e vindas, até então.

\section{Considerações finais}

O sentido do passado da Educação Profissional no Brasil desvela o conteúdo e a forma de como se construiu historicamente. De um lado, permanece predominantemente assentada como modo educativo de menor valor, pois, traz a marca de seus vínculos com a classe trabalhadora, constituída por pretos, brancos pobres, abandonados, desvalidos, marginais: os "desclassificados". Estes podem continuar analfabetos ou ter uma formação elementar ou um pouco mais complexa, mas que possa ser instrumentalizada pelos senhores ou empresários, nos engenhos, nos latifúndios, nas indústrias e por que não, nos bancos. Caso não sejam incluídos, podem até morrer, nas ruas escuras da cidade, na vastidão do campo, no mar, e nos caminhos cheios de muros. É o sentido da "necropolítica". Caso vivam ou sobrevivam, uma formação profissional, assistencialista, pode servir como instrumento de inculcação ideológica e adestramento do corpo e da vida destes trabalhadores ao "destino da sua (má) sorte".

Por outro lado, este passado/presente indica, a partir de um olhar lapidado pela totalidade dos fenômenos sociais, as mais profundas misérias. Evidencia o continuado estado escravista desta sociedade, pois, permanecem as condições miseráveis e perversas de superexploração dos trabalhadores. Vide as reformas trabalhista e previdenciária aprovadas a partir de 2017. Traz frequentemente à tona, os pactos entre a elite brasileira para a realização do assalto ao Estado e a riqueza produzida por estes trabalhadores. A democracia é para "inglês ver". Limitada e restrita aos interesses privados destas elites. Não é possível e nem necessária uma educação integrada, humanista, democrática para estes "desvalidos da sorte".

Contudo, o passado diz ao presente e ao futuro que outras possibilidades foram construídas. Em uma sociedade altamente excludente, autoritária e perversa com os que produzem a riqueza na base, forjam-se, pelas mãos calejadas e o pensamento vivo dos trabalhadores, experiências educativas que visam a superação do que moralmente as "permanências" colocam. Este sentido, que é o da existência ética, com todos os compromissos políticos necessários para sua efetivação, deve ser o sentido do passado a ser apropriado, sempre a favor e nunca contra os trabalhadores. 
Referências

BRASIL. Lei de Diretrizes e Bases da Educação Nacional. Lei no 9394, de 20 de dezembro de 1996. Estabelece as diretrizes e bases da educação nacional. Diário Oficial da União, Brasília, 1996.

BRASIL. Plano Nacional de Educação. Disponível em: http://pne.mec.gov.br/18-planossubnacionais-de-educacao/543-plano-nacional-de-educacao-lei-n-13-005-2014. Acesso em $30 / 05 / 2020$.

BRASIL. Plano Nacional de Qualificação do Trabalhador-PLANFOR: reconstruindo a institucionalidade da educação profissional no Brasil. Brasília, 1998.

BRASIL. Decreto no 5.840, de 13 de julho de 2006. Institui o Programa Nacional de Integração da Educação Profissional com a Educação Básica na modalidade de Educação de Jovens e Adultos- PROEJA. Diário Oficial da União, de 14/07/2006.

BRASIL. Portaria MEC n ${ }^{\mathbf{0}}$ 168, de 07 de março de 2013. Dispõe sobre a oferta da BolsaFormação no âmbito do Programa Nacional de Acesso ao Ensino Técnico e Emprego (Pronatec), de que trata a Lei no 12.513, de 26 de outubro de 2011, e dá outras providências. Brasília, DF: 07 de março de 2013.

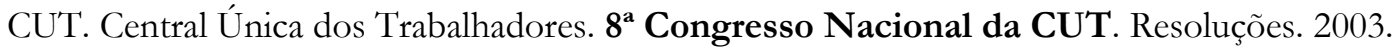
Acesso: 17/09/2015. Disponível em:http://www.cut.org.br/system/uploads/document/26dd9521c0b73c55e06b41 f8bdbd5 a25/file/8-congresso-nacional-da-cut-8-concut-03-a-07-06-2003.pdf Acesso em 3 de agosto de 2019.

HOBSBAWM, Eric. Sobre história. São Paulo: Companhia das Letras, 1998.

FERNANDES, Florestan. A revolução burguesa no Brasil: ensaio de interpretação sociológica. Rio de Janeiro: Zahar, 1975.

FREITAS, Luiz Carlos. O PISA e a geocultura da desigualdade meritocrática. Disponível em: https: //avaliacaoeducacional.com/2019/12/08/o-pisa-e-a-geocultura-da-desigualdademeritocratica/ Acesso em 30/05/2020.

FRIGOTTO, Gaudêncio. Educação, crise do trabalho assalariado e do desenvolvimento: Teorias em conflito. In: FRIGOTTO, Gaudêncio (org.). Educação e crise do trabalho: Perspectivas de final de século. Petrópolis, RJ: Vozes, 1998.

FRIGOTTO, Gaudêncio; CIAVATTA, Maria; RAMOS, M. A política de educação profissional no governo Lula: um percurso histórico controvertido. Educação \& Sociedade, Campinas, V. 26, n.92, Especial, 2005. Disponível em: http//www.cedes.unicamp.br Acesso em 06 de agosto de 2019.

GENTILI, P. Neoliberalismo e educação: manual do usuário. In: SILVA, T. T. da \& GENTILI, P. (Orgs.). Escola S.A.: quem ganha e quem perde no mercado educacional do neoliberalismo. Brasília, DF: CNTE, 1996. Disponível em:

http://static.recantodasletras.com.br/arquivos/4002523.pdf. Acesso formato eletrônico de 2017 em 29/05/2020.

KUENZER, Acácia Zeneida. Da dualidade assumida à dualidade negada: o discurso.

Disponível em https://www.scielo.br/scielo.php?pid=S0101-

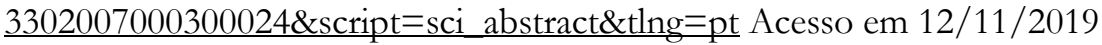

MACHADO. Maria Margarida. A educação de jovens e adultos no século XXI - da

alfabetização ao ensino profissional. Revista Inter-Ação. UFG. Goiânia, v. 36, n. 2, p. 393-412, jul-dez. 2011.

MANFREDI, S. M. Educação profissional no Brasil. São Paulo: Cortez, 2002.

MARX, Karl. O 18 Brumário de Luís Bonaparte: Karl Marx e Friedrich Engels, Obras

Escolhidas, V. 01. São Paulo: Alfa-ômega, s/d2. 
MARX, Karl. Teses sobre Feuerbach: Karl Marx e Friedrich Engels, Obras Escolhidas, V. 03. São Paulo: Alfa-ômega, s/d1.

MEC. Base Nacional Comum Curricular (Texto final). Brasília: 2018. Disponível em: http://basenacionalcomum.mec.gov.br/images/BNCC_EI_EF_110518_versaofinal_site.pdf Acesso em 29/05/2020.

MORAES, Carmen Sylvia V. Educação de jovens e adultos trabalhadores de qualidade: regime de colaboração e Sistema Nacional de Educação. Educação e Sociedade, Campinas v. 34n. 124, p. 970-1001, jul-set, 2013.

MOURA, Dante H. A relação entre a Educação Profissional e a Educação Básica na CONAE 2010: possibilidades e limites para a construção do novo Plano Nacional de Educação. Revista Educação e Sociedade, Campinas, jul.-set. 2010. Acesso: 13 jul. 2015. Disponível em: http://www.scielo.br/pdf/es/v31n112/12.pdf

OLIVEIRA, F. de. Crítica à razão dualista: o ornitorrinco. São Paulo: Boitempo, 2003.

OLIVEIRA, M. A. M. Políticas públicas para o ensino profissional: o processo de desmantelamento dos CEFETS. Campinas, SP: Papirus, 2003 a.

VARGAS, Nilton. Gênese e difusão do Taylorismo no Brasil. Revista Ciências Sociais Hoje, 1985.

\footnotetext{
Notas:

1 Professora efetiva do Instituto Federal de Educação, Ciência e Tecnologia de Goiás, Doutora em Educação. Pesquisadora na área de Educação Profissional e Tecnológica, Formação Integrada e Educação de Jovens e Adultos. Membro Núcleo de Pesquisa e Estudos em Educação e Formação de Trabalhadores - NUPEEFT http://dgp.cnpq.br/dgp/espelhogrupo/166236 CV: $\quad$ http://lattes.cnpq.br/7690161558708230 Orcid: https://orcid.org/0000-0002-0270-8251 E-mail: mdrcastro16@gmail.com

2 Profissional da Educação da Rede Municipal de Educação/RME de Goiânia-GO. Doutorado pelo Programa de PósGraduação em Educação da Universidade de Brasília- UNB Profissional da Educação da Rede Municipal de Educação/RME de Goiânia-GO. CV: http://lattes.cnpq.br/5189182534267867 Orcid: https://orcid.org/0000-00020378-3245 E-mail: cbc2111@gmail.com

${ }^{3}$ Professor do Instituto Federal de Educação Ciência e Tecnologia de Goiás - Câmpus Goiânia: Goiania, Goiás, BR Membro do NUPEMARX (Núcleo de Pesquisa Marxista) - http://dgp.cnpq.br/dgp/espelhogrupo/26656 Membro Núcleo de Pesquisa e Estudos em Educação e Formação de Trabalhadores - NUPEEFT http://dgp.cnpq.br/dgp/espelhogrupo/166236 CV: $\quad$ http://lattes.cnpq.br/9167766831005467 Orcid: https://orcid.org/0000-0001-9496-3454 E-mail: sebcbar3@gmail.com
} 